\title{
Postbooster Antibodies from Humans as Source of Diphtheria Antitoxin
}

\section{Jesús F. Bermejo-Martin, Ana Avila-Alonso, Milagros González-Rivera, Eduardo Tamayo, Jose María Eiros, Raquel Almansa}

Diphtheria antitoxin for therapeutic use is in limited supply. A potential source might be affinity-purified antibodies originally derived from plasma of adults who received a booster dose of a vaccine containing diphtheria toxoid. These antibodies might be useful for treating even severe cases of diphtheria.

A lthough diphtheria is an almost forgotten disease in industrialized countries, sporadic cases still occur. Possible reasons for these cases include partial failure of vaccine compliance, antivaccine campaigns, inadequate booster regimens, and immunosenescence. Health authority interest in this disease was rekindled after a nonvaccinated boy in Spain died of systemic diphtheria in June 2015 and 9 cases of cutaneous diphtheria among refugees were notified by Denmark, Sweden, and Germany in 2015 (1). According to the World Health Organization, 7,321 cases of diphtheria were reported worldwide in 2014. In the early 1890s, Emil von Behring used serum from a hyperimmune horse (challenged with sublethal dose of Corynebacterium diphtheriae) to develop equine diphtheria antitoxin (DAT), which seemed to confer passive immunity to patients with diphtheria (2). Subsequently, use of equine DAT to treat this disease became common. Uncontrolled but large studies of mortality rates from that time suggested effectiveness of equine DAT use; however, double-blinded randomized studies conducted by Adolf Bingel in 1918 concluded that equine DAT offered no benefit over serum from nonhyperimmune horses (not challenged with $C$. diphtheriae) (2). Although modern efficacy studies are lacking, equine DAT is still the recommended treatment for diphtheria, listed among the World Health Organization essential medicines (3). When administered early in the clinical course of disease, treatment with DAT can be lifesaving for patients with toxin-induced systemic symptoms.

A large proportion of European countries do not stockpile DAT, and many countries have experienced difficulties

Author affiliations: Hospital Clínico Universitario de Valladolid,

Valladolid, Spain (J.F. Bermejo-Martin, A. Avila-Alonso, E. Tamayo,

J. María Eiros, R. Almansa); Hospital General Universitario

Gregorio Marañón, Madrid, Spain (M. González-Rivera)

DOI: http://dx.doi.org/10.3201/eid2207.151670 replacing expired stockpiles $(3,4)$. As highlighted by the European Centre for Disease Prevention and Control (1), the current lack of DAT in the European Union is a concern. DAT is not produced or licensed in the United States or in most European countries; it is imported from Brazil under an Investigational New Drug protocol (5).

Equine DAT can induce anaphylactic reactions (a test for sensitivity to DAT should be conducted before each administration) (5). The European Centre for Disease Prevention and Control and the US Centers for Disease Control and Prevention encourage searching for new providers of equine DAT and promote the development of alternative antitoxins of human origin. The definitive solution will probably come from monoclonal antibodies (4) or synthetic molecules such as nucleic acid aptamers. These new molecules could constitute an unlimited source of DAT, with a low risk for hypersensitivity reactions. Unfortunately, these alternatives are not yet available and will need to undergo thorough regulatory processes before being approved for use in humans. We therefore describe the potential role of human plasma from vaccinated volunteers as a source of DAT.

Plasma from vaccinated persons is used to produce Anthrasil (Cangene Corporation, Winnipeg, Manitoba, Canada), a fully human polyclonal antianthrax intravenous immunoglobulin (IVIG) licensed in the United States. Antitetanus immunoglobulin is produced from plasma of young volunteers who received a booster dose of the tetanus-diphtheria vaccine.

The successful implementation of vaccination programs in industrialized and many developing countries indicates that most of these populations have antibodies against the diphtheria toxin. Nonetheless, the geometric mean concentration of $\operatorname{IgG}$ against diphtheria toxin in plasma of vaccinated adults who received the last dose of tetanus-diphtheria vaccine in their adolescence is not much over $0.3 \mathrm{IU} / \mathrm{mL}$ (6). For diphtheria treatment, $20,000-100,000$ IU of DAT is needed; the dose depends on disease severity (5). In consequence, producing DAT from plasma obtained from the general population could not be cost-effective because large volumes would be needed to obtain a dose of DAT with enough potency for clinical use.

An alternative could be to obtain plasma from adult donors who recently received a booster dose of vaccine. Researchers have observed that during the diphtheria epidemic that emerged in the newly independent states of the 
former Soviet Union from 1991 through 1994, booster vaccination of convalescent patients led to enhanced antidiphtheria toxin titers $(3,7)$. Seroepidemiologic studies evaluating the effect of booster vaccination of adults against diphtheria support this finding. Booster vaccination of adults induces up to $10 \mathrm{IU} / \mathrm{mL}$ of $\mathrm{IgG}$ against diphtheria toxin in plasma 4 weeks after vaccination $(8-13)$ (Table). The use of conjugate vaccines, or a high vaccine dose, could yield the highest plasma concentrations of DAT after a booster dose of vaccine ( 9 ).

Assuming use of revaccinated donor plasma with the highest titer, IVIG with a DAT potency up to 60-100 IU/ $\mathrm{mL}$ could be obtained by using the standard methods for producing IVIG (3). This concentration could be enough to treat moderate forms of diphtheria (those with skin lesions only, laryngeal disease, or nasopharyngeal disease) (5). The European Pharmacopoeia recommends that the potency of equine-derived DAT be no less than 1,000 IU/ $\mathrm{mL}$ (3). To treat severe diphtheria, a dose of 100,000 IU, obtained by using a 5\% IVIG solution with potency of $100 \mathrm{IU} / \mathrm{mL}$, would require 1.6 liters of product, a substantially high volume that would be very difficult to administer to a child.

This major drawback could be solved by using antigen-specific antibody purification. The process is simple: the antigen is immobilized in a solid phase so that the antibodies that bind specifically to it are retained during addition of plasma. Bound antibody can be recovered by acid elution (14). This method has been successfully used to purify specific antibodies from plasma or normal IVIG for research and development purposes (15). In 1988, also in an experimental context, M. Sutjita et al. demonstrated that this approach was useful for concentrating DAT from human serum; they used a diphtheria toxoid-Sepharose 4B (Sigma Aldrich, St. Louis, MO, USA) affinity column (14). In consequence, this approach could be used to purify DAT from plasma of revaccinated persons or from commercial immunoglobulins (i.e., the antitetanus immunoglobulin itself or nonspecific IVIG), which contains variable concentrations of DAT (online Technical Appendix, http:// wwwnc.cdc.gov/EID/article/22/7/15-1670-Techapp1.pdf). This concentrated DAT could be useful for treating diphtheria of any severity in adults and children, with very low risk of inducing hypersensitivity reactions.

A potential drawback of affinity purification is that the obtained DAT could be denatured by acid elution. This risk could be minimized by immediately neutralizing $\mathrm{pH}$ by adding $1 \mathrm{~mol} / \mathrm{L}$ Tris, followed by dialysis with phosphatebuffered saline. The obtained product should undergo the same biological agent removal processes as those used for standard IVIG (i.e., chemical inactivation, heat inactivation, nanofiltration, and precipitations). Neutralization potency of DAT obtained from human plasma should be assigned according to the Vero cell cytotoxicity assay and the guinea pig lethality model; the 1st International Standard for Diphtheria Antitoxin Human should be used as the reference antitoxin (National Institute for Biological Standards and Control code 10/262).

A limitation of using DAT obtained from human plasma is the potential cost. Some developing countries, where most cases of diphtheria occur, could not afford it. Production costs and the price of each dose of human DAT could be reduced by using as source the same plasma obtained from the donors recruited to produce the antitetanus immunoglobulin. Industrialized countries could also donate doses of this human DAT to developing countries.

\begin{tabular}{|c|c|c|c|c|c|}
\hline \multirow[b]{3}{*}{ Ref. } & \multicolumn{2}{|c|}{ Study population } & \multirow[b]{3}{*}{ Vaccine } & \multicolumn{2}{|c|}{ Immunogenicity, GMC IU/mL (95\% Cl) } \\
\hline & Mean age, y (S) & & & & \\
\hline & or range) & No. & & Before booster & After booster \\
\hline \multirow[t]{2}{*}{$(8)$} & $40.1(13.63)$ & $\begin{array}{c}1,44 \\
8\end{array}$ & $\begin{array}{c}0.5 \text { mL Tdap (Boostrix; GlaxoSmithKline } \\
\text { Biologicals, Rixensart, Belgium) }\end{array}$ & $0.4(0.4-0.4)$ & $4.7(4.4-5.1)$ \\
\hline & $40.4(13.48)$ & 728 & $\begin{array}{l}0.5 \text { mL Tdap (Adacel; Sanofi Pasteur, } \\
\text { Swiftwater, PA, USA) }\end{array}$ & $0.5(0.4-0.5)$ & $5.0(4.6-5.4)$ \\
\hline \multirow[t]{2}{*}{ (9) } & $31.7(15-69)$ & 64 & $\begin{array}{l}0.5 \mathrm{~mL} \text { of Tdap (Sanofi Pasteur Limited, } \\
\text { Toronto, ON, Canada) after previous } \\
\text { vaccination with MCV4D (Menactra; Sanofi } \\
\text { Pasteur, Swiftwater, PA, USA) }\end{array}$ & $4.45(2.77-7.15)$ & $8.70(6.59-11.5)$ \\
\hline & & 379 & $\begin{array}{c}0.5 \mathrm{~mL} \text { Tdap (Sanofi Pasteur Limited, } \\
\text { Toronto) }\end{array}$ & $0.13(0.11-0.16)$ & $2.17(1.84-2.56)$ \\
\hline \multirow[t]{2}{*}{$(10)$} & $19.4(1.2)$ & 55 & 0.2 mL DTap (Kaketsuke, Kumamoto, Japan) & $0.22(0.16-0.30)$ & $4.29(3.53-5.21)$ \\
\hline & $19.4(0.8)$ & 56 & $0.5 \mathrm{~mL}$ DTap (Kaketsuke) & $0.21(0.15-0.30)$ & $6.28(4.86-8.11)$ \\
\hline \multirow[t]{2}{*}{$(11)$} & $66.0(59-91)$ & 252 & 0.5 mL Tdap (Repevax; Sanofi Pasteur MSD & $0.04(0.03-0.06)$ & $1.09(0.81-1.46)$ \\
\hline & $24.0(20-33)$ & 21 & GmbH, Leimen, Germany) & $0.14(0.05-0.33)$ & $4.16(2.36-7.34)$ \\
\hline \multirow{3}{*}{$\begin{array}{l}(12) \\
(13)\end{array}$} & $21.1(0.31)$ & 74 & $0.5 \mathrm{~mL}$ Tdap (Boostrix) & $0.3(0.2-0.4)$ & $6.0(4.7-7.7)$ \\
\hline & $26.5(18-52)$ & 401 & $\begin{array}{c}0.5 \mathrm{~mL} \text { TdaP (Statens Serum Institut, } \\
\text { Copenhagen, Denmark) }\end{array}$ & $0.11(0.9-0.14)$ & $4.60(4.03-5.26)$ \\
\hline & $26.1(18-55)$ & 399 & $0.5 \mathrm{~mL}$ diTeBooster (Statens Serum Institut) & $0.11(0.09-0.14)$ & $5.54(4.00-5.15)$ \\
\hline
\end{tabular}


Plasma from young adults receiving a booster dose of vaccine could represent a potential source of human DAT. Antigen-affinity antibody purification could help to produce a highly concentrated DAT from this plasma, useful for treating even the most severe forms of diphtheria. This approach could help mitigate the limited access to this essential medicine.

\section{Acknowledgement}

We thank Juan I. Jorquera, Francesc Camps, Salvador Grancha, Joan Balcell, and the Grifols Corporation for helpful discussions for the elaboration of this manuscript. We also thank the Consejería de Sanidad de Castilla y León (Valladolid, Spain) and the Instituto de Salud Carlos III (Madrid, Spain) for their support of our research programs.

Dr. Bermejo-Martin is head of the Infection \& Immunity Medical Investigation Unit at the Hospital Clínico Universitario, Instituto de Estudios de Ciencias de la Salud de Castilla y León, in Valladolid, Spain. His research interests include immunity in severe infections, such as those caused by emerging viruses and sepsis.

\section{References}

1. European Centre for Disease Prevention and Control. Rapid risk assessment: a case of diphtheria in Spain [cited $2015 \mathrm{Jul} 7$ ]. http://ecdc.europa.eu/en/publications/Publications/diphtheria-spainrapid-risk-assessment-june-2015.pdf

2. Opinel A, Tröhler U, Gluud C, Gachelin G, Smith GD, Podolsky SH, et al. Commentary: the evolution of methods to assess the effects of treatments, illustrated by the development of treatments for diphtheria, 1825-1918. Int J Epidemiol. 2013;42:662-76. http://dx.doi.org/10.1093/ije/dyr162

3. Wagner KS, Stickings P, White JM, Neal S, Crowcroft NS, Sesardic D, et al. A review of the international issues surrounding the availability and demand for diphtheria antitoxin for therapeutic use. Vaccine. 2009;28:14-20. http://dx.doi.org/10.1016/ j.vaccine.2009.09.094

4. Both L, White J, Mandal S, Efstratiou A. Access to diphtheria antitoxin for therapy and diagnostics. Euro Surveill 2014;19:pii:20830

5. Centers for Disease Control and Prevention. Use of diphtheria antitoxin (DAT) for suspected diphtheria cases [cited 2015 Aug 19]. http://www.cdc.gov/diphtheria/downloads/protocol.pdf

6. Wagner KS, White JM, Andrews NJ, Borrow R, Stanford E, Newton E, et al. Immunity to tetanus and diphtheria in the UK in 2009. Vaccine. 2012;30:7111-7. http://dx.doi.org/10.1016/ j.vaccine.2012.09.029
7. Bissumbhar B, Rakhmanova AG, Berbers GA, Iakolev A, Nosikova E, Melnick O, et al. Evaluation of diphtheria convalescent patients to serve as donors for the production of anti-diphtheria immunoglobulin preparations. Vaccine. 2004; 22:1886-91. http://dx.doi.org/10.1016/j.vaccine.2003.11.006

8. Blatter M, Friedland LR, Weston WM, Li P, Howe B. Immunogenicity and safety of a tetanus toxoid, reduced diphtheria toxoid and three-component acellular pertussis vaccine in adults 19-64 years of age. Vaccine. 2009;27:765-72. http://dx.doi.org/ 10.1016/j.vaccine.2008.11.028

9. Halperin SA, McNeil S, Langley J, Blatter M, Dionne M, Embree J, et al. Tolerability and antibody response in adolescents and adults revaccinated with tetanus toxoid, reduced diphtheria toxoid, and acellular pertussis vaccine adsorbed (Tdap) 4-5 years after a previous dose. Vaccine. 2011;29:8459-65. http://dx.doi.org/ 10.1016/j.vaccine.2011.07.068

10. Hara M, Okada K, Yamaguchi Y, Uno S, Otsuka Y, Shimanoe C, et al. Immunogenicity and safety after booster vaccination of diphtheria, tetanus, and acellular pertussis in young adults: an open randomized controlled trial in Japan. Clin Vaccine Immunol. 2013;20:1799-804. http://dx.doi.org/10.1128/CVI.00490-13

11. Kaml M, Weiskirchner I, Keller M, Luft T, Hoster E, Hasford J, et al. Booster vaccination in the elderly: their success depends on the vaccine type applied earlier in life as well as on prevaccination antibody titers. Vaccine. 2006;24:6808-11. http://dx.doi.org/10.1016/j.vaccine.2006.06.037

12. Mertsola J, Van Der Meeren O, He Q, Linko-Parvinen A, Ramakrishnan G, Mannermaa L, et al. Decennial administration of a reduced antigen content diphtheria and tetanus toxoids and acellular pertussis vaccine in young adults. Clin Infect Dis. 2010;51:656-62. http://dx.doi.org/10.1086/655825

13. Thierry-Carstensen B, Jordan K, Uhlving HH, Dalby T, Sørensen C, Jensen AM, et al. A randomised, double-blind, non-inferiority clinical trial on the safety and immunogenicity of a tetanus, diphtheria and monocomponent acellular pertussis (TdaP) vaccine in comparison to a tetanus and diphtheria (Td) vaccine when given as booster vaccinations to healthy adults. Vaccine. 2012;30:546471. http://dx.doi.org/10.1016/j.vaccine.2012.06.073

14. Sutjita M, Hohmann A, Comacchio R, Bradley J. Polyspecific human and murine antibodies to diphtheria and tetanus toxoids and phospholipids. Clin Exp Immunol. 1988;73:191-7.

15. Estabrook MM, Jarvis GA, McLeod Griffiss J. Affinity-purified human immunoglobulin $\mathrm{G}$ that binds a lacto-N-neotetraosedependent lipooligosaccharide structure is bactericidal for serogroup B Neisseria meningitidis. Infect Immun. 2007;75: 1025-33. http://dx.doi.org/10.1128/IAI.00882-06

Address for correspondence: Jesús F. Bermejo-Martin, Infection \& Immunity Medical Investigation Unit, Hospital Clínico Universitario de Valladolid, SACYL/IECSCYL, Avenida Ramón y Cajal, 3, 47005 Valladolid, Spain. Email: jfbermejo@saludcastillayleon.es 